\title{
DETERMINATION OF PARAMETERS OF AEROSOL CHARGING PROCESS WHEN SPRAYING PLANTS
}

\author{
Sergey Antonov \\ Stavropol State Agrarian University, Russia \\ antonov_serg@mail.ru
}

\begin{abstract}
Insufficient amount of fertilizer applied during the main tillage highlights the top dressing of fertilizer solutions. The main advantage of foliar application is the quick delivery of nutrients by absorbing them through leaves and other parts of plants. High efficiency of foliar application is achieved by increasing the coverage of the plant leaf area. A new generation of machine resource-saving fertilizer application technologies will increase the efficiency. One of the promising technologies is electrostatic spraying of crops. It will reduce the consumption of micronutrient fertilizers, optimize the size of the deposited drops, increase the amount of fertilizer drops applied to the leaves. Electrostatic spraying provides good surface coverage. It allows to use a process automation system and increase productivity and efficiency. The essence of the electrostatic method consists in spraying a working solution with the transmission of an electric charge to the aerosol particles. Charged aerosol particles are uniformly deposited on an oppositely charged surface. In industry, this method has found great practical application. The use of this method in agriculture is difficult due to a number of problems. One of the problems is working with biological objects. Therefore, when developing devices for electrostatic charging of aerosols, this problem must be taken into account. The proposed method for charging aerosols can eliminate the influence of the device on biological objects and increase the electrical safety of the system. For effective operation of the device, it is necessary to experimentally determine the parameters of work when spraying plants.
\end{abstract}

Keywords: aerosol, electrostatic field, foliar application, fertilizers, spraying, high voltage.

\section{Introduction}

To increase agricultural productivity, it is necessary to use modern methods of fertilizer application. The effectiveness of using foliar application is due to the elimination of macro- and microelement delivery from the roots of the plant to its upper part. Long-term exploitation of agricultural land without the required replenishment of micronutrients leads to their depletion, as a result to reduction in yields and a decrease in the nutritional value of agricultural products. However, high fertilization rates adversely affect the environment. About $30 \%$ of pesticides and mineral fertilizers applied to the fields enter water bodies. At the same time, a decrease in the volume of agrichemical application leads to reduction in yields. The problem of rational use of chemicals and their savings is relevant at the present time [1-3].

The cost of fertilizers increases every year, while liquid complex fertilizers are $20 \%$ lower than similar solid fertilizers. The growth rate of the cost to buy fertilizers sometimes exceeds the cost of additional yield obtained from their application. To ensure cost recovery for the purchase of fertilizers, it is necessary to strictly observe agrotechnical requirements for spraying technologies and technical hardware. Machines must provide uniform droplet atomization of the working fluid, a stable concentration and flow rate of the fluid during the entire period of the unit operation, a predetermined rate of agrichemical consumption per unit of treated area, uniform coverage of the entire plant with fluid and minimal loss of the working fluid.

The permissible deviation of the fluid flow per unit area should not exceed $10 \%$ of the specified norm. The size of the dispersed liquid droplets with hydraulic sprayers during normal spraying of plants should be within $200-550$ microns with $70-3301 \cdot \mathrm{ha}^{-1}$. The coating density is $80 \%$ of the upper part of the leaf surface and $60 \%$ of the lower. Thus, it is necessary to optimize the processes of fertilizers application, while maintaining efficiency at a sufficiently high level [4].

One of the ways to increase the efficiency of liquid mineral fertilizers is to reduce their consumption by improving the technologies and applied technical hardware. The most promising is the use of electrically charged aerosols [5].

\section{Materials and methods}

To increase the efficiency of fertilizer application, it is proposed to use the system considered in [6;7]. The experimental device is designed to work with four sprayers (Fig. 1). The aim of the 
research is to determine the spray quality indicators and the efficiency of the aerosol particle deposition at various parameters of the ionizer. The essence of the system is that the air passing through the ionizer acquires a charge. Further, this ionized air is mixed with a fertilizer solution. When leaving the sprayer, the charge is transferred to the droplets of aerosol, which adhere to the leaf of the plant.

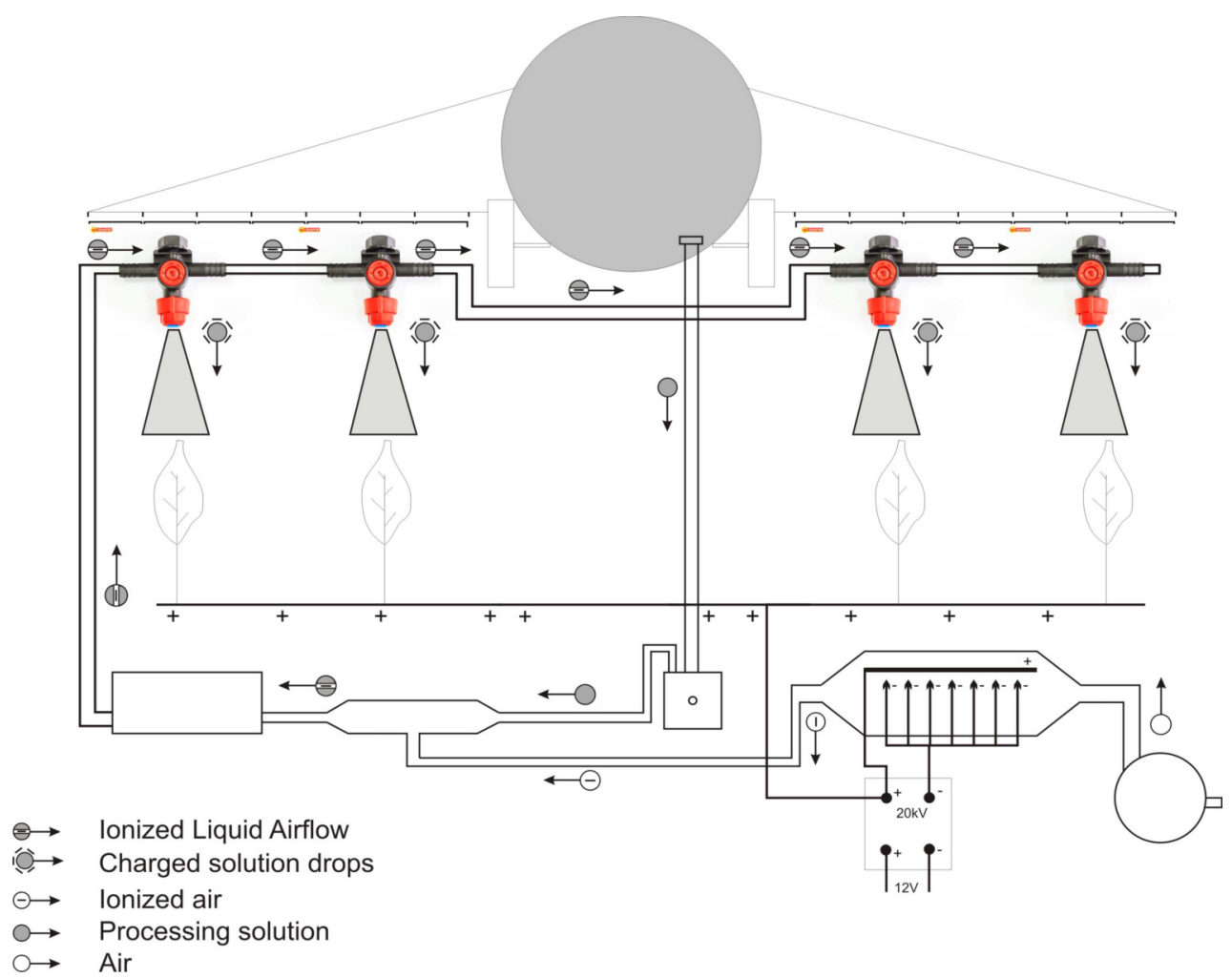

Fig. 1. Effective plant spraying system

The ionizer is the main element of the proposed system. The analysis of the existing designs of ionizers identified their shortcomings [8]. One of the main deficiencies is the possibility of potential drift onto the metal parts of the spraying system. Considering all the shortcomings, we offer the design of the ionizer shown in Fig. 2.

The ionizer for the crop spraying system (Fig. 2) consists of a nozzle 1, which is necessary for connecting to the system trunk, an ionizer case 2 made of plastic, a needle electrode system 3 made of wolframite, mounting bolts 4 , a plate electrode 5 made of metal-clad glass textolite and a high voltage source 6 .
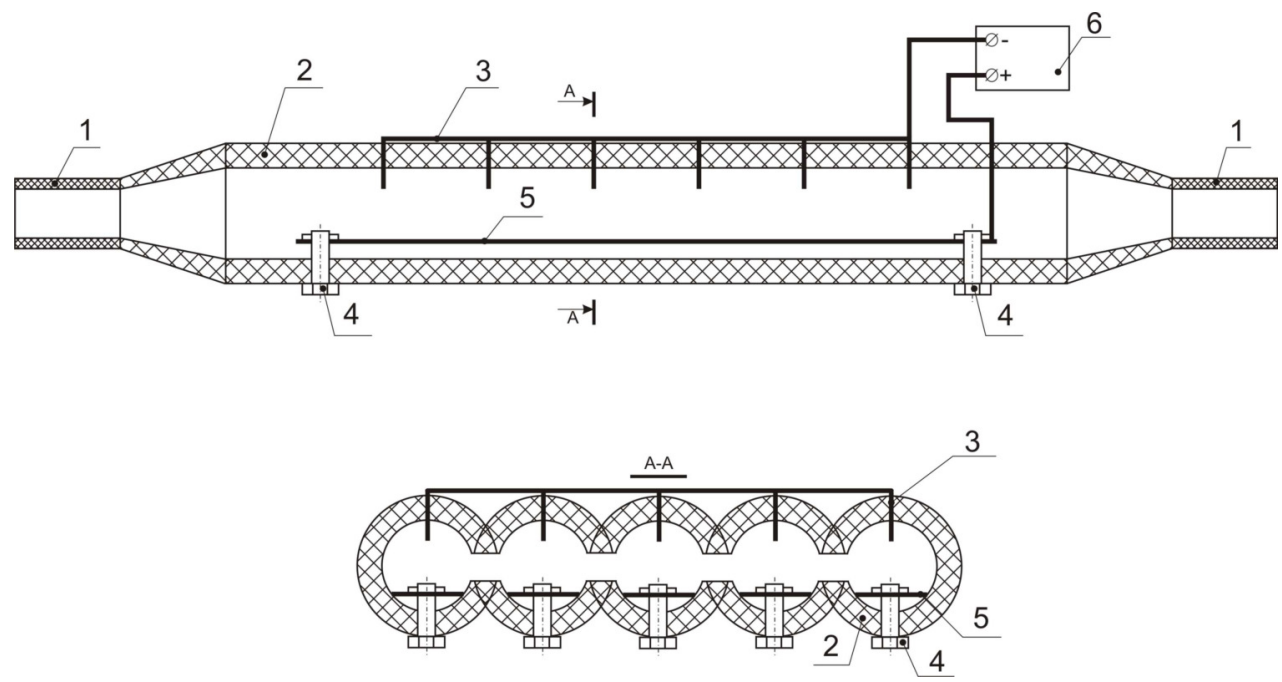

Fig. 2. Advanced ionizer for crop spraying system 
The ionizer works as follows (Fig. 3): using the nozzle 1, the ionizer is fixed to the trunk of the crop spraying system. The needle electrode system 3 is connected to the negative terminal, and the plate electrode is connected to the positive terminal of the high voltage source 6. Voltage of at least $1 \mathrm{kV} \cdot \mathrm{cm}^{-1}$ is required to start the air ionization process. The ionizer zone I is characterized by a supply of clean air.

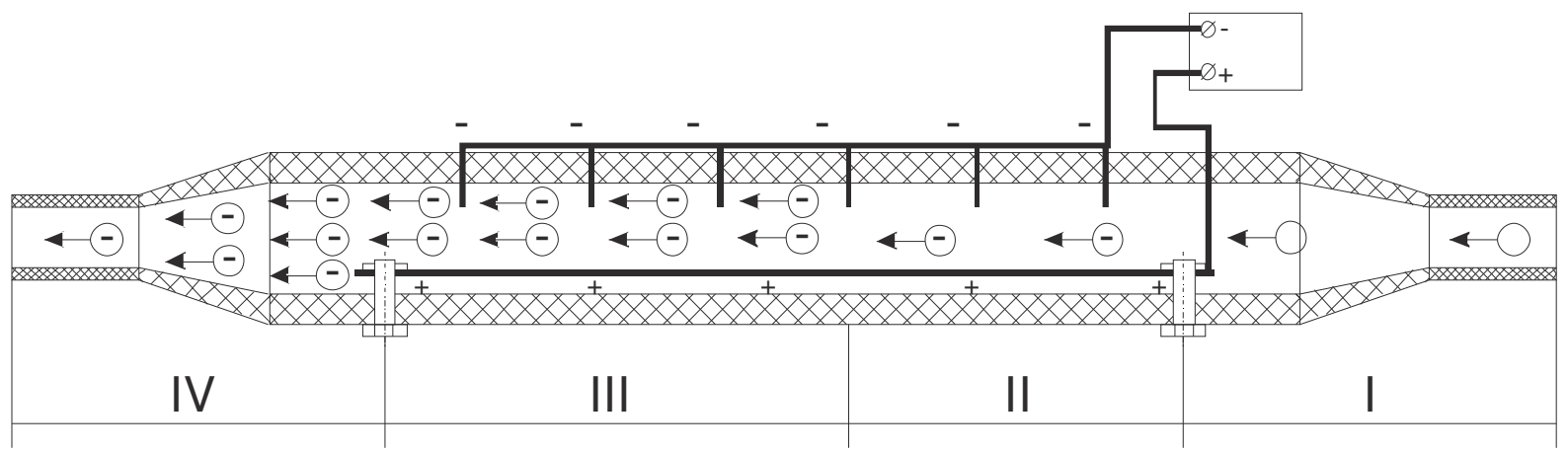

Fig. 3. Operating principle of the ionizer for a crop spraying system

When clean air enters zone II, passing through a high-intensity electric field $\left(5-10 \mathrm{kV} \cdot \mathrm{cm}^{-1}\right)$, it partially begins (from 0 to $500 \cdot 10^{3} \mathrm{~cm}^{-3}$ ) to acquire a negative electric charge - , in zone III negative aero ions increase to $5000 \cdot 10^{3} \mathrm{~cm}^{-3}$. In zone IV, ionized air is compressed and sent to the main trunk of the crop spraying system.

The design parameters for manufacturing of the ionizer are shown in Fig. 4.
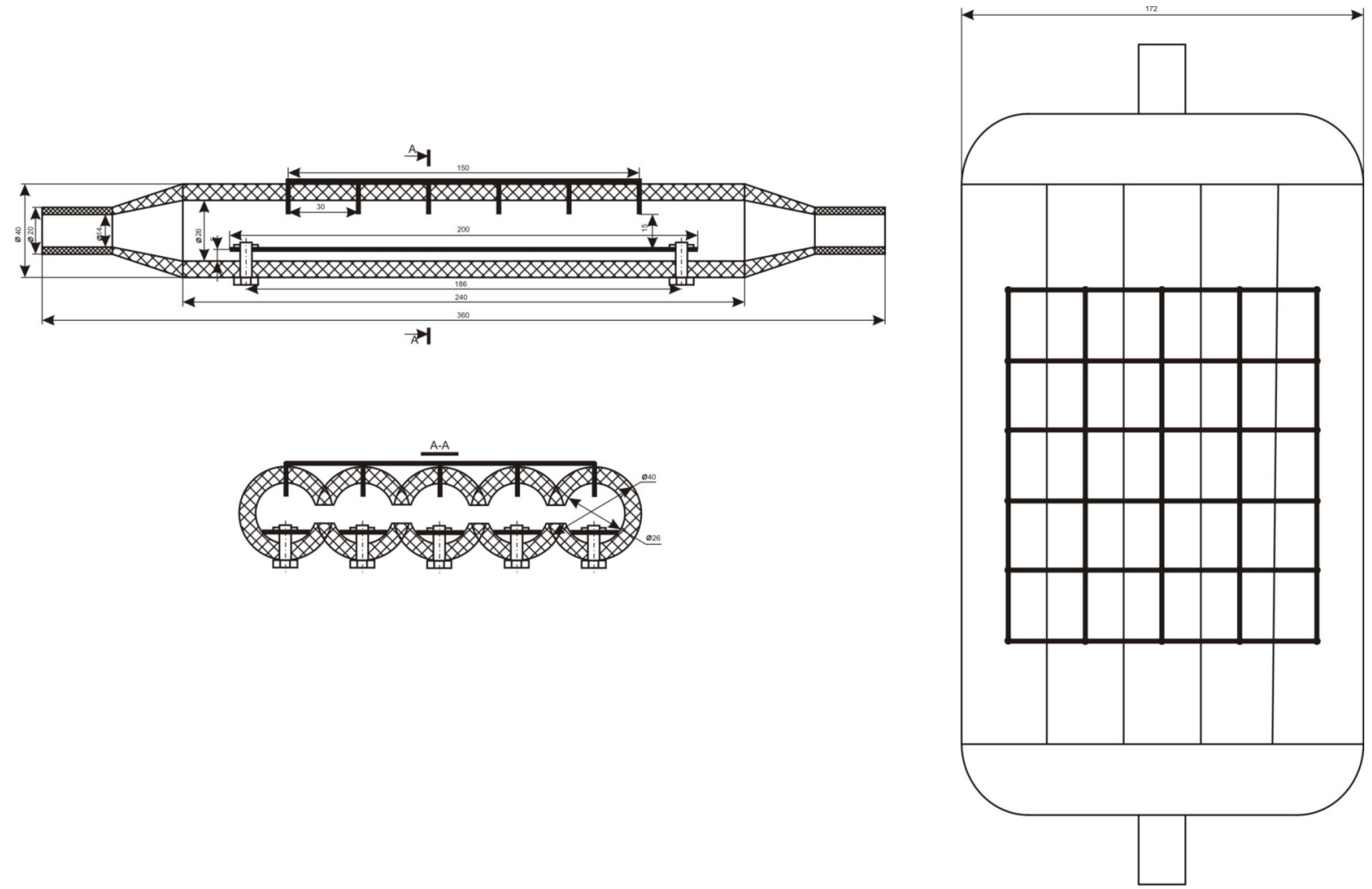

Fig. 4. Advanced ionizer design for crop spraying systems

The material for manufacturing of the ionizer is preferably plastic with a wall thickness of more than $4 \mathrm{~mm}$. Outer diameter $40 \mathrm{~mm}$, inner diameter $26 \mathrm{~mm}$. The length of the ionizer is $360 \mathrm{~mm}$, the width is $172 \mathrm{~mm}$. The length of the plate electrode is $200 \mathrm{~mm}$, it is made of metal-clad glass textolite and fixed inside the ionizer using mounting bolts. The distance between the needles of the needle system is at least $30 \mathrm{~mm}$. The needle system is made of wolframite, which contributes to the most efficient production of negatively charged ions. 


\section{Results and discussion}

Tests of high-voltage equipment and the ionization system, together with the spraying system, are necessary to study the basic energy characteristics of the working process of aerosol electric charging. For this purpose, it is necessary to use registration cards, on which the number and size of received droplets are fixed, both on the back and front sides.

As the results of processing the data (Table 1) obtained by microscopy of registration cards show, when using electrostatic charging of droplets in a spray torch of a sprayer, an increase in the density of the surface coating of cards with drops of the working solution is observed. If, when applying the solution without preliminary electric charging, the average coating density of the front leaf surface was about $124 \mathrm{pcs} \cdot \mathrm{cm}^{-2}$, and there were practically no drops on the reverse side, then, when using the liquid-air mixture ionization system with a tubular ionizer, this value was 164 and $85 \mathrm{pcs} \cdot \mathrm{cm}^{-2}$, respectively, for the front and back of the leaf.

Average number of drops in size groups

\begin{tabular}{|c|c|c|c|c|c|c|c|}
\hline \multirow{2}{*}{$\begin{array}{l}\text { Surface } \\
\text { position }\end{array}$} & \multicolumn{6}{|c|}{ Number of drops in size group, microns } & \multirow{2}{*}{ Tota } \\
\hline & $20-50$ & $50-80$ & 80-100 & 100-150 & 150-200 & $>\mathbf{2 0 0}$ & \\
\hline & \multicolumn{7}{|c|}{ Without electrification } \\
\hline Front side & 0 & 5 & 9 & 31 & 53 & 26 & 124 \\
\hline Back side & 0 & 1 & 6 & 9 & 15 & 2 & 33 \\
\hline \multicolumn{8}{|c|}{ Electrostatic treatment } \\
\hline Front side & 7 & 8 & 19 & 47 & 52 & 31 & 164 \\
\hline Back side & 9 & 15 & 27 & 17 & 11 & 6 & 85 \\
\hline
\end{tabular}

Thus, the studies show that the use of electrostatic charging of the resulting aerosol makes it possible to increase the coating density of the treated surface by $20-75 \%$, in particular on the reverse (back) side, which is especially important to increase the efficiency of the use of agrichemicals and reduce their consumption. In addition, when working with a tubular ionizer, the fraction of small droplets in the total spectrum (Table 2), precipitating under the influence of Coulomb forces and not just gravity, increases 3-4 times in the spray spectrum. In turn, an increase in the fraction of small droplets in the spectrum entailed an increase in coating uniformity by $57 \%$.

Table 2

Drop distribution by size groups

\begin{tabular}{|c|c|c|c|c|c|c|}
\hline \multirow{2}{*}{ Leaf surface } & \multicolumn{7}{|c|}{ Relative number of drops, \% in the size group, microns } \\
\cline { 2 - 7 } & $\mathbf{2 0 - 5 0}$ & $\mathbf{5 0 - 8 0}$ & $\mathbf{8 0 - 1 0 0}$ & $\mathbf{1 0 0 - 1 5 0}$ & $\mathbf{1 5 0 - 2 0 0}$ & $>\mathbf{2 0 0}$ \\
\hline \multicolumn{7}{|c|}{ Without electrification } \\
\hline Front side & 0 & 4.1 & 7.3 & 25.0 & 42.7 & 20.9 \\
\hline Back side & 0 & 3.0 & 18.2 & 27.3 & 45.4 & 6.1 \\
\hline \multicolumn{7}{|c|}{ Needle electrode system } \\
\hline Front side & 4.3 & 4.8 & 11.6 & 28.7 & 31.7 & 18.9 \\
\hline Back side & 10.5 & 17.6 & 31.8 & 20.0 & 12.9 & 7.2 \\
\hline
\end{tabular}

To assess the consumption of electrical energy by the equipment of the ionization system, current and voltage measurements in the circuit were carried out. The values obtained during the experiment are shown in Table 3.

Table 3

Energy consumption of aerosol electrification system for input voltage $14 \mathrm{~V}$

\begin{tabular}{|c|c|c|c|c|c|}
\hline $\begin{array}{c}\text { Consumption } \\
\text { input current, } \mathbf{A}\end{array}$ & $\begin{array}{c}\text { Output } \\
\text { voltage, } \\
\mathbf{k V}\end{array}$ & $\begin{array}{c}\text { Consumption } \\
\text { current, } \boldsymbol{\mu A}\end{array}$ & $\begin{array}{c}\text { Transferred } \\
\text { charge, } \\
\mathbf{\mu C} \cdot \mathbf{m l}^{\mathbf{- 1}}\end{array}$ & $\begin{array}{c}\text { Total energy } \\
\text { consumption, } \\
\mathbf{W}\end{array}$ & $\begin{array}{c}\text { Energy } \\
\text { consumption for } \\
\text { each nozzle, } \mathbf{W}\end{array}$ \\
\hline 4.2 & 14.0 & 2.7 & 0.11 & 38 & 9.5 \\
\hline 4.7 & 18.0 & 4.3 & 0.18 & 77 & 19.25 \\
\hline 5.9 & 22.0 & 5.7 & 0.22 & 125 & 31.25 \\
\hline
\end{tabular}


Thus, it was found that at the highest voltage of electrification, the energy consumption for each nozzle is about $31.25 \mathrm{~W}$, and therefore, when installing electrode systems over the entire width of the sprayer boom, the power consumption will be 500 watts.

Studies of the charged aerosol droplet deposition identified the need for efficient use of electric aerosol charging technology for treating plants during the growing season.

Increasing the number of charged aerosol droplets both on the front and on the back side of the leaf allows to reduce the consumption rate of the working fluid (up to $501 \cdot \mathrm{ha}^{-1}$ ), reduce the loss of chemicals and increase the degree of environmental efficiency.

The installation of high-voltage equipment must be carried out on a specially prepared site in order to ensure sufficient ventilation and distance from the nodes and pipelines of the hydraulic sprayer system.

The data obtained during the experiment show that with an increase in the applied voltage, an increase in the polydispersity index of the droplet spray spectrum occurs, which indicates a wide dispersion of droplets in size groups due to the appearance and prevalence of the fraction of small droplets in the total amount. This is confirmed by the obtained values of the weighted average median diameter of the droplets. And although the phenomenon of increased spray polydispersity is negative, in our case it is inevitable, which makes this spraying technology more universal, because according to the recommendations for various types of biologically-active preparations and various crops, the optimal droplet size upon application varies from 80 to $200 \mu \mathrm{m}$. Based on a given range of droplet sizes, we can conclude that the obtained results completely satisfy these requirements, since, considering the features of the change in the weighted average median droplet diameter in the spectrum, it can be concluded that with an increase in the corona discharge on the electrodes, it was possible to reduce the average statistical droplet size on the front side of leaves and increase this value for the back (leeward) surfaces.

\section{Conclusions}

Analysis of the research results allows us to draw the following conclusions:

1. The parameters of the most effective operating mode of the sprayer ionization system will be as follows: voltage $-18 \mathrm{kV}$ (voltage $5.5 \mathrm{kV} \cdot \mathrm{cm}^{-1}$ ); working fluid consumption rate $-58 \mathrm{~cm}^{3} \cdot \mathrm{s}^{-1}$; speed of the ionized air flow $-4-5 \mathrm{~m} \cdot \mathrm{s}^{-1}$; speed of the spraying system $1.8 \mathrm{~m} \cdot \mathrm{s}^{-1}$.

2. The effect of processing the lower surface depends on the charging voltage, and this dependence is manifested to a greater extent at sufficiently high speeds of the spraying system.

3. The density of the coating on the upper side of the leaves is about 3-4 times more than the lower. The upper side, regardless of the aerosol charge level, is processed efficiently, and the level of processing efficiency of the lower surface depends on the aerosol charge degree.

4. The optimal voltage value for a dense coating of the upper side of the leaf is $18 \mathrm{kV}$ and it does not depend on changes in other factors in the study area.

The electric charging of the ion-air mixture contributes to effective deposition of droplets, allows to provide the necessary rate of agrotechnical requirements at low fertilizers consumption and relatively high speeds.

\section{References}

[1] Архипов В. А. Аэрозольные системы и их влияние на жизнедеятельность (Aerosol systems and their influence on vital functions) / V.A. Arkhipov, U. M. Sheremetyeva. - Tomsk: TPU Publishing House, 2007. - 136 p. (In Russian).

[2] Antonov S.N., Gabriyelyan S.Z., Mastepanenko M.A., Zorina E.B., Nozdrovicky L The device of magnetic processing of water for boiler greenhouse. Research in agricultural engineering. Vol. 62, 2016, Special Issue: pp. 27-33.

[3] Matthews G.A. Pesticide Application Methods. 3rd ed. - Wiley-Blackwell Science Ltd., 2000. $448 \mathrm{p}$.

[4] Nasr G.G., Yule A.J., Bendig L. Industrial Sprays and Atomization: Design, Analysis and Applications. Springer-Verlag London, 2002. 501 p. 
[5] Турчин И.А. Электризация рабочих жидкостей (Electrification of working fluids). // Journal of Plant Protection. - №9. - 1987. - pp. 29-36. (In Russian).

[6] Antonov S., Nikitenko G., Adoshev A., Dorozhko S., Devederkin I., Method of effective spraying plants with drop charge of fertilizer solution by ionized air. Engineering for rural development, Jelgava Latvia, 2018, pp. 519-523.

[7] Antonov S., Development of a high voltage source for spraying plants with ionized aerosol. Engineering for rural development, Jelgava Latvia, 2019, pp. 808-813.

[8] Avdeeva V.N., Antonov S.N., Molchanov A.G., Devederkin I.V. Disinfecting of winter wheatgrain withelectrophysical factors. Engineering for rural development, Jelgava, Latvia, 2017, pp. 323-327. 